ARCHIVO ESPAÑOL DE ARTE, LXXXVII, 346

ABRIL-JUNIO 2014, pp. 157-162

ISSN: 0004-0428, eISSN: 1988-8511

doi: $10.3989 /$ aearte.2014.11

\title{
VARIA
}

\section{UNA PINTURA ATRIBUIBLE A ANTONIO DE PEREDA EN VILLASECA DE LA SAGRA (TOLEDO)}

\author{
AnTonio José DíAz FernándeZ \\ Doctor en Historia del Arte por la UNED
}

\begin{abstract}
Aquí se da a conocer una pintura de La aparición de la Virgen a San Bernardo, de la iglesia de Ntra. Sra. de los Peligros de Villaseca de la Sagra (Toledo), documentada en 1650 y cuyo estilo la aproxima a obras del pintor barroco Antonio de Pereda.

Palabras clave: La Virgen; San Bernardo; Antonio de Pereda; Pintura madrileña; S. XVII; Pintura barroca española; Villaseca de la Sagra (Toledo).
\end{abstract}

\section{A PAINTING ATTRIBUTABLE TO ANTONIO DE PEREDA IN VILLASECA DE LA SAGRA (TOLEDO)}

This study presents the painting The Virgin Appearing to Saint Bernard, located in the church of Ntra. Sra. de los Peligros in the town of Villaseca de la Sagra (Toledo), documented in 1650, the style of which comes close to that of the Madrid Baroque artist Antonio de Pereda.

Key words: Virgin Mary; St Bernard; Antonio de Pereda; painting in Madrid; $17^{\text {th }}$ century; Spanish Baroque painting; Villaseca de la Sagra (Toledo).

En junio de 1996 finalizaba la restauración de una interesante pintura en óleo sobre lienzo, de regulares dimensiones $(181,5 \times 147,5 \mathrm{~cm})$, representando el asunto de la Aparición de la Virgen a San Bernardo y que la intervención encontró con rasgos perdidos de firma en la parte inferior izquierda, aunque su extremo deterioro la hacía ilegible y nos privaba del conocimiento de su autor ${ }^{1}$. Lo cierto es que este estimable cuadro venía perteneciendo a la Fundación Hospital de San Bernardo, histórica obra pía fundada por el Licenciado don Bernardo García de San Pedro, Visitador por el Arzobispado de Toledo en Madrid y su partido y conventos de monjas, a la vez que Examinador General de su Arzobispado; voluntad que fue expresada en el testamento abier-

\footnotetext{
${ }^{1}$ Ingresada en octubre de 1995 con número de registro P-683 en la Escuela Superior de Conservación y Restauración de Bienes Culturales del Ministerio de Educación y Ciencia, quien a través del órgano diocesano de la Delegación de Patrimonio del Arzobispado de Toledo la devolvía a su legítima propietaria, la Fundación Hospital de San Bernardo de Villaseca de la Sagra (Toledo), depositaria de un legado piadoso y cultural fraguado en 1650 bajo Patronato de Legos.
} 
to tras su muerte ante el escribano de Madrid Antonio Cadenas en 17 de mayo de 1650, y llevada a buen término por sus albaceas el maestro fray Pedro Yáñez, Prior de Santo Tomás de esa villa en su convento de Atocha y Predicador de S. M., y el Doctor don Francisco López de Mena, Capellán de Honor de S. M. y Canónigo de la Magistral de Alcalá de Henares, a la vez que administrador del convento de Santa Isabel la Real de Madrid, a la sazón primo del difunto y confidente de sus intenciones piadosas. La principal disposición del finado era la creación en su villa natal, Villaseca de la Sagra, diócesis de Toledo, de un patronato de legos y la construcción de un hospital para pobres con título de San Bernardo y una capilla para su entierro con la advocación de Ntra. Sra. de los Peligros, reservando de entre sus numerosos bienes privados, según inventario post mortem realizado en Madrid en 28 de mayo de 1650, los que adornaban su oratorio y principalmente ".. un quadro para el altar de nra S. a con su niño en los vraços y señor san berd. ${ }^{\circ}$ con su marco negro" ${ }^{\text {. }}$ Y, en efecto, la institución se creó con el primordial cometido de construir capilla funeraria y hospital. El proyecto edilicio habría de recaer en el arquitecto agustino Fray Lorenzo de San Nicolás quien trazó enteramente la obra de la pequeña iglesia, y a la que alude inequívocamente en su tratado Arte y Uso de la Arquitectura, Segunda Parte (1666), al hacer recuento de las bóvedas octogonales encamonadas realizadas por él hasta entonces $^{3}$. Esta circunstancia nos advierte de la gran dependencia del medio artístico madrileño que mostraron tanto el fundador Bernardo García como los primeros patronos administradores, por su residencia habitual en la Villa y Corte, entendiendo por ello que la referida pintura que presidía el oratorio de tan digno presbítero en Madrid era obra sin duda de pintor o taller acreditado. Por tanto, y una vez cumplidas las mandas testamentarias, suponemos la definitiva presencia del mencionado cuadro sobre el altar mayor de la nueva capilla hospitalaria de Villaseca de la Sagra desde su consagración en septiembre de 1679 y hasta que en 1772 se decidió incorporarla al ático de un retablo tardo-barroco que se construía entonces, si bien los daños causados en 1936 hicieron que el cuadro se desmontara por la caída del soporte superior y se guardara la tela sobre su precario bastidor en las dependencias de la capilla hasta la señalada restauración de 1996, promovida por la última junta de patronos de la institución benéfica ${ }^{4}$.

Evidentemente estamos ante una composición pictórica de planteamiento barroco en la convenida línea diagonal, pero que contiene un equilibrado movimiento entre los dos planos encontrados que sitúan a las dos figuras principales, relacionadas en una misma escala (fig. 1). Así, a la izquierda y sobre un suelo desprovisto o neutro se aploma la figura, piramidal, del monje reformador, arrodillada y de tres cuartos, envuelta en su imponente y voluminosa cogulla alba, y en actitud arrobada, con un leve giro de su cabeza hacia su izquierda y las manos cruzadas sobre el pecho, conformando el lado terrenal de la escena, espacio señalado asimismo por el cortinaje que pende a sus espaldas de la mitad superior del cuadro aunque hábilmente recogido por una

${ }^{2}$ Escritura de constituciones de la Fundación, Archivo Histórico Provincial de Toledo (AHPT), Protocolo 3712 , folio 324, escribano Juan Flores González. Este extenso documento de 1669 contiene traslado tanto del testamento como del inventario de bienes del mencionado fundador, en las diligencias llevadas a cabo por sus testamentarios en la fundación efectiva del patronato, designación de capellanes y administradores de la obra pía, con la redacción de los capítulos de gobierno del establecimiento hospitalario. Las advocaciones de la institución venían a rememorar la gran devoción que su propio tío Blas García (†1635), a la sazón Secretario de Felipe IV, tuvo en vida hacia la milagrosa Virgen de los Peligros, tan venerada en el convento de la Piedad Bernarda de Madrid, conocido como "las Vallecas", de la calle de Alcalá, y cuyos legados censales incorporó la posterior fundación de Bernardo García.

3 DíAz FERNÁNDEZ, 1989: 233-275.

${ }^{4}$ Hoy, reinstalado en el remate superior del retablo mayor tras la restauración llevada a cabo en este inmueble y sus bienes artísticos entre 2009 y 2011, con el cambio de titularidad en la gestión de este patrimonio una vez extinguida la histórica fundación en 2008 y haciéndose cargo del edificio el Ayuntamiento de la villa bajo la tutela de la Junta de Comunidades de Castilla-La Mancha, y convertido parcialmente en centro cultural — con el nombre de San Bernardo- pero reservando para el culto la que fue capilla hospitalaria con todos sus enseres.

Arch. esp. arte, LXXXVII, 346, ABRIL-JUNIO 2014, 157-162 ISSN: 0004-0428, eISSN: 1988-8511, doi: 10.3989/aearte.2014.11 


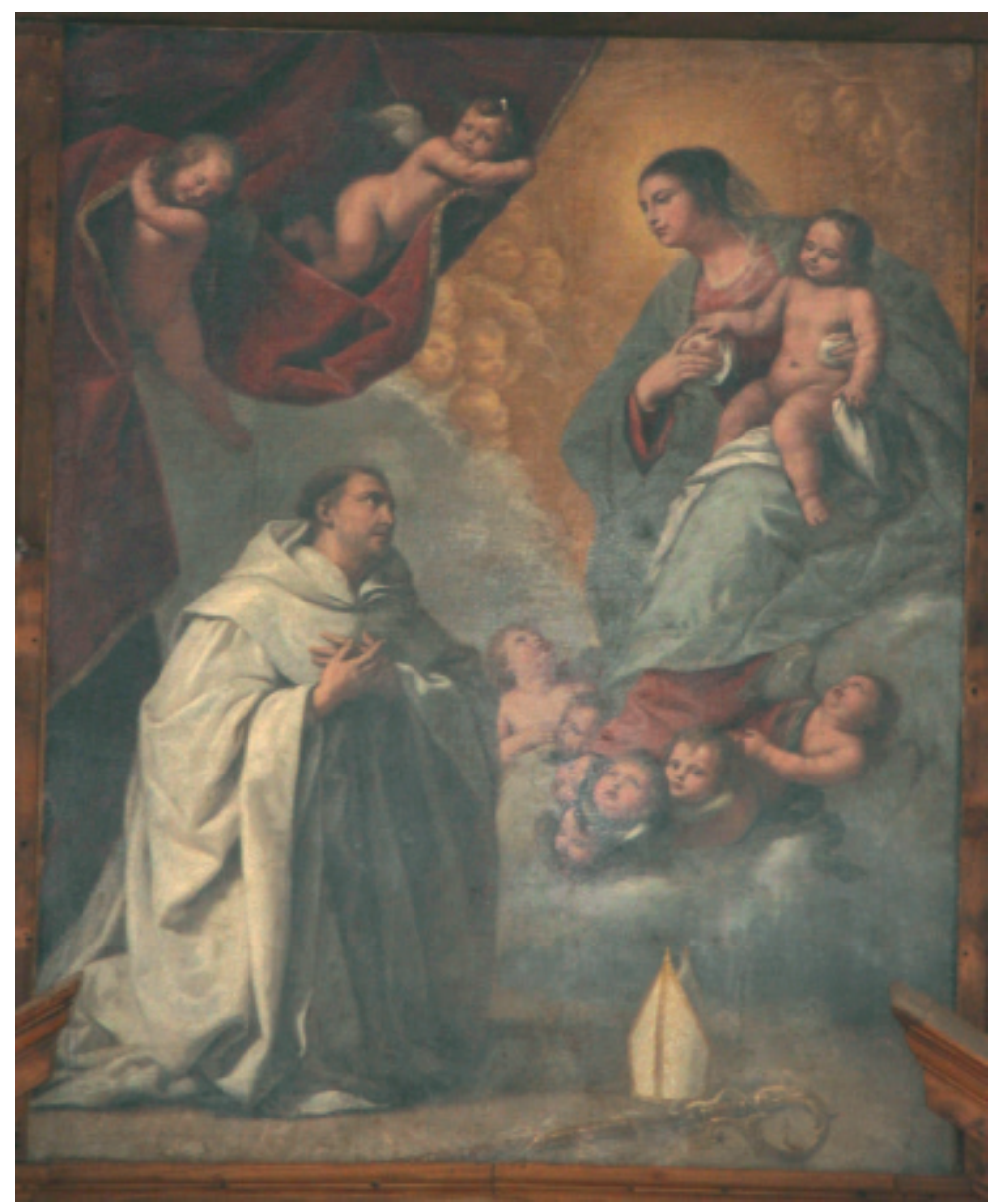

Fig.1. Pintura de la Aparición de la Virgen a San Bernardo, atribuible a Antonio Pereda. Iglesia de Ntra. Sra. de los Peligros. Villaseca de la Sagra (Toledo).

pareja de querubines en posición contrapuesta que lo alzan sin apenas esfuerzo intentando descubrir la visión mística. En la mitad derecha del lienzo se abre el indefinido espacio del milagro, donde irrumpe en posición perpendicular y en toda su figura la Virgen con el Niño a caballo de su rodilla izquierda; ella sentada sobre un trono suspendido de nubes del que asoman dos querubines de media figura de cabezas alzadas y una punta de cinco cabezas aladas que hacen escabel a sus pies y la elevan sobre los atributos del monje, el báculo tendido en el suelo y una mitra levantada, que le confieren iconográficamente la dignidad de abad y el obispado rehusado. El celaje nebuloso del fondo se enciende con la luminosidad jalonada por una rueda de cabezas de angelitos rubios que hace de respaldo dorado y centrada aureola a la Señora, de cuyo pecho, levemente oprimido por su mano derecha y en el que posa igualmente su manecita el Niño, desciende un finísimo hilo de leche mística hacia los labios del contemplativo monje, informando de que el asunto no es otro que el de la Lactación de San Bernardo.

La composición recuerda inmediatamente en el esquema y disposición de las figuras el cuadro de mayor tamaño que Bartolomé E. Murillo pintó en 1655 para el convento sevillano de San Clemente, y hoy en el Museo del Prado, aunque aquí la Virgen se yergue en pie, y en el conjunto del cuadro hay mayor ímpetu y movimiento. Un precedente temático y compositivo de este lienzo del gran artista sevillano podría ser la pintura de su paisano Juan de Roelas, La Lactación de San Bernardo, realizada en 1611 para la iglesia del Hospital de San Bernardo de la ciudad hispalense (hoy

Arch. esp. arte, LXXXVII, 346, ABRIL-JUNIO 2014, 157-162

ISSN: 0004-0428, eISSN: 1988-8511, doi: 10.3989/aearte.2014.11 
en el Palacio Arzobispal). Lejos de una y otra fecha, y por supuesto del mundo sevillano, la pintura conservada en Villaseca de la Sagra, que hay que remitir a fecha anterior a 1650, es necesario relacionarla con obras del segundo cuarto del siglo XVII e indudablemente dentro del ámbito de lo madrileño. Pensemos por ello en la decoración pictórica emprendida en 1634 en el Salón de Reinos del palacio del Buen Retiro, que determinó el encuentro de meritorios pintores y otros artistas, para comprender el alto empeño de la pintura cortesana y su inevitable prestigio, haciendo de la capital del Reino el mejor y más cualificado escenario de arte. Realmente, la composición toledana bien podría derivar en lo sustancial del cuadro de Vicente Carducho titulado La visión de San Bernardo, de 1634, y hoy en el Museo de Santa Cruz de Toledo, que se pintó para el convento Imperial de monjas cistercienses de San Clemente de Toledo. . Aun así, se evidencia más proximidad compositiva entre la pintura de la institución villasecana y la más temprana de las sevillanas arriba mencionada, fruto de la utilización de un mismo modelo, en este caso, de un grabado, sugerido quizás por la estampa 19 de la Vita et miracula divi Bernardi Clarevalensis abbatis Opera e industria, impreso en Roma en 1587. Tal es la coincidencia en la disposición cruzada de las manos del santo como la aparición de la Virgen en actitud bastante similar. Pero si se defendiese la cercanía a la citada composición de Carducho, es obvio que resaltan más las diferencias tanto técnicas como estéticas al comparar ambos cuadros, consecuencia de su distanciamiento estético. Y, por demás, es tan distinto al tema de Alonso Cano del Museo del Prado, de 1657-60, y tan lejano del barroquismo con que Juan Carreño de Miranda representa el mismo asunto en el del Museo parroquial de la Colegiata de la Asunción en Pastrana (Guadalajara) ya de 1668.

Técnicamente, la de Villaseca era una tela muy fatigada, lo que obligó a su forración, y se presentaba ejecutada con poca película pictórica; caracterizándose por la pincelada precisa, plana y sin empastes, homogénea y lisa por lo general, con ligero empastamiento en los colores oscuros, y con una paleta cromática de predominio de tierras, azules y rojos, según refiere el informe restaurador.

En esta representación que nos ocupa, desprovista de referencias arquitectónicas, tan sólo las espaciales, la figura del santo (fig. 2) evidencia una gran monumentalidad, bien dibujada y de razonable naturalismo, pues el modelo es un hombre bien parecido, en actitud calmada y emoción contenida, y una cabeza individualizada, tonsurada e hirsuta, de rasgos maduros y mirada bondadosa, circundada por una apenas perceptible aureola, y unas manos de buen modelado y gesto de gran naturalidad; figura engrandecida por la luminosidad del ropaje resuelto en ordenados pliegues, en una presentación algo zurbaranesca y recurriendo a la misma incidencia de la luz por el lado izquierdo desde fuera del cuadro y que aquí modela con efectismo los amplios movimientos del ropaje, pero también con menor fuerza escultórica, proyectando sin dramatismo la sombra del cuerpo a la zona muerta dentro del cuadro, sobre el propio suelo en el que se disponen la mitra de sencillo bordado y el báculo abacial, en diagonal y parcialmente representado, con su ornamentada voluta y un sutil velo que lo serpentea. Aunque también podríamos encontrar en la apostura del santo ecos de las figuras de blancos cartujos del citado Carducho, pero lejos del interés por la luz contrastada o el duro claroscuro.

El empleo de las masas de ángeles, quizá sea otra peculiaridad del estilo compositivo de Pereda. Y notamos en el estudio de las cabezas de los ángeles características reiteradas en otras obras donde aparecen éstos. Siempre se focaliza una cabeza cuya mirada de soslayo se dirige al espectador, y en este caso es la central a los pies de la Virgen, tan similar en otras cabezas infantiles como en la del propio paje de La Rendición de Génova por el Segundo Marqués de Santa Cruz (1634) del

\footnotetext{
5 Revuelta Tubino, 1987: 32; corresponde al n. ${ }^{\circ}$ 48, Inv. Gral. 10.744. El mismo convento de bernardas conserva aún otra interesante pintura con el mismo tema, obra de Luis Tristán, cuyo esquema compositivo está invertido respecto a nuestra pintura pero muestra al santo en actitud parecida con las manos cruzadas sobre el pecho, siguiendo un modelo de San Jacinto ante la Virgen de Ludovico Carracci, Pérez SÁnCHEZ, 1982: 203.
}

Arch. esp. arte, LXXXVII, 346, ABRIL-JUNIO 2014, 157-162 ISSN: 0004-0428, eISSN: 1988-8511, doi: 10.3989/aearte.2014.11 


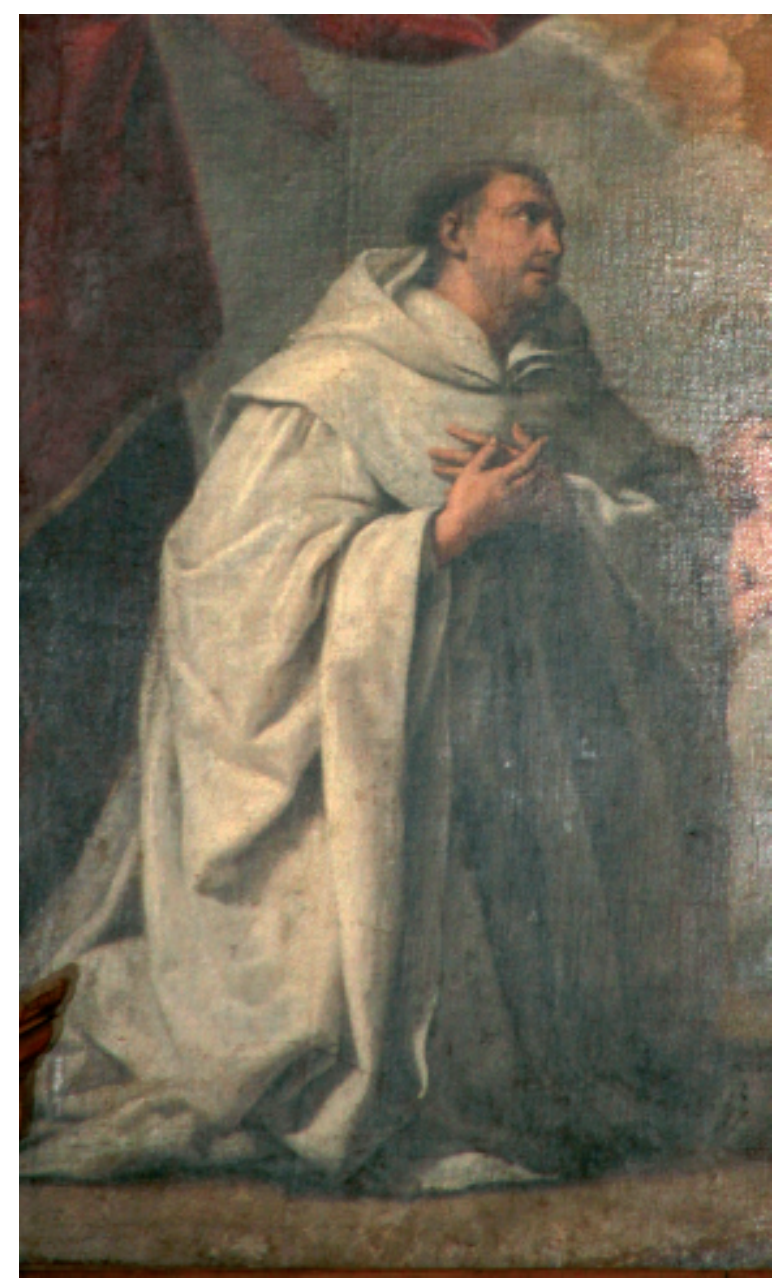

Fig. 2. Detalle de la figura de San Bernardo.

Museo del Prado, como en la cabeza a los pies de San José en el lienzo principal de las Carmelitas Descalzas de Toledo (1640), y como en la del ángel mancebo del grupo derecho representado en el cuadro del convento de la Encarnación de Madrid, Profesión de la infanta Margarita (1650). Cabezas de rizosos cabellos rubios con pequeño bucle en la frente, junto a otras de forma más redonda debido a su pelo corto y pegado animan el escabel de la Virgen (fig. 3).

Por otra parte, tal vez resulte poco habitual el recurso del cortinaje en otras obras religiosas de Pereda, y más frecuente en otros pintores barrocos de la segunda mitad del siglo, aunque ya advertido su uso en composiciones de Alonso Cano, quien lo muestra también recogido por querubines hacia la izquierda en su lienzo de la Anunciación (1645) del retablo de Ntra. Sra. de la Paz, de la actual catedral de Getafe (Madrid). Aunque también era una constante en los retratos de aparato propios de esta primera mitad del siglo. Sin embargo, en la obra que aquí presentamos se ve como un elemento que perturba en cierto modo la visualización de la escena pese a su necesaria función de referencia espacial y en cierto modo narrativa, pues los ángeles parecen contribuir al hecho visionario descorriendo el pesado cortinaje de la estancia donde reza el religioso. No obstante, es preciso fijarse en los dos ángeles que lo sujetan para advertir en sus posturas que reproducen uno y otro casi las que tienen los dos ángeles que coronan a la Virgen en el cuadro de la Inmaculada del Museo de Bellas Artes de Lyon o el del mismo tema del Museo del Prado (firmada en 1636) del propio Pereda.

Por todo lo expuesto, hemos querido ver en este lienzo de Villaseca de la Sagra concomitancias con aspectos de la obra de Antonio de Pereda y Salgado (1611-1678), pintor ya maduro en la cuarta década de la centuria y autor de temas religiosos de ese momento como la Inmaculada para el hermano del cardenal de Crescenzi (1635), Los desposorios de la Virgen con San José para los capuchinos de Valladolid (1640), el mencionado lienzo de Santa Teresa y San Agustín de las Carmelitas Descalzas de Toledo (1640) más los cuadritos en los áticos de los retablos colaterales (1644), Cristo varón de dolores (1641), San Jerónimo penitente y San Pedro liberado por el ángel (1643), estos tres en el Museo del Prado, y El Niño Jesús de las calaveras de la iglesia de las Maravillas de Madrid (1644) .

\footnotetext{
6 Angulo IñIguez, Pérez SÁnchez, 1983. Pérez SÁnchez, 1979.
} 


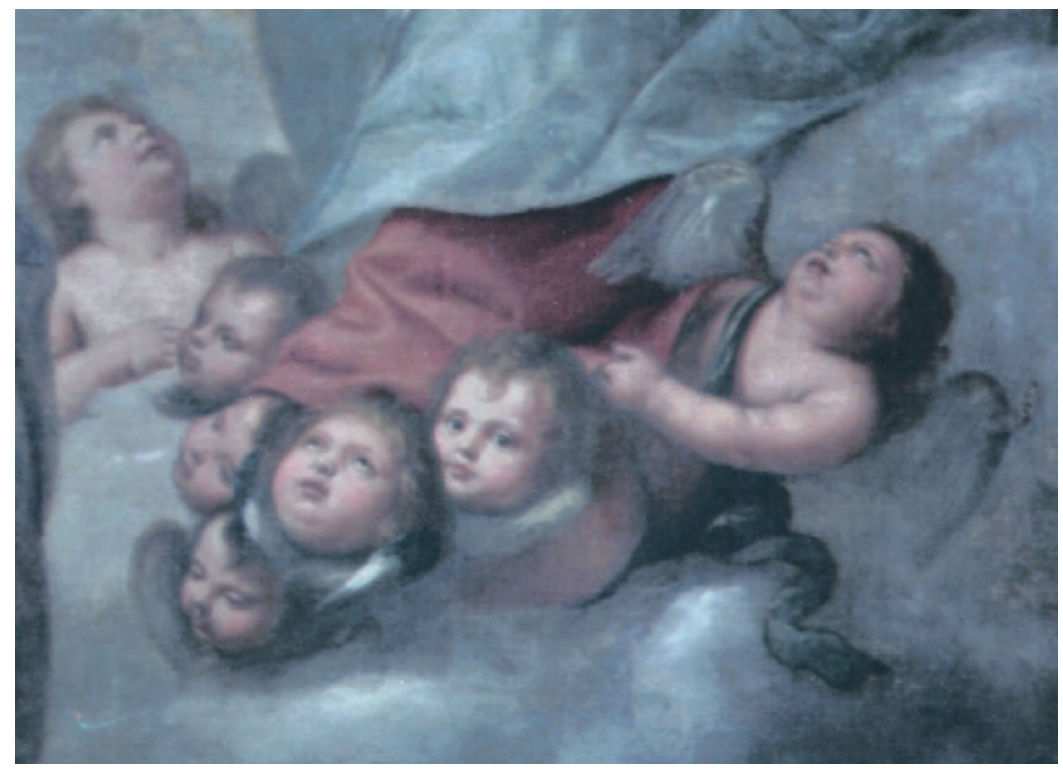

Fig. 3. Detalle del trono de ángeles a los pies de María.

Por tanto, se puede pensar que el lienzo de la Virgen y San Bernardo de localización toledana al ser obra de encargo particular de un respetable clérigo cortesano y destinada en un primer momento para el altar de su oratorio privado, fue concebida por el pintor bajo presupuestos de clara y ordenada composición, con figuras bien definidas dentro de un sencillo escenario y supeditadas a la verosimilitud de la historia narrada, con un carácter cercano y piadoso para representar la aparición y confortación de María al "doctor melifluo", y con una correcta realización pictórica, sobre una economía de medios y sin la necesidad de mayores artificios compositivos ni más intención persuasiva que la visión directa y humanizada del milagro. Y por lo antes comentado, no dudando en atribuir esta obra al pintor madrileño Antonio de Pereda y sugerir su datación en la década de 1640 a 1650.

\section{BIBLIOGRAFÍA}

Angulo Iñiguez, D. y Pérez Sánchez, A. E., La pintura madrileña del segundo tercio del siglo XVII, Madrid, 1983.

Díaz Fernández, Antonio J., "Obras del arquitecto Fray Lorenzo de S. Nicolás en Villaseca de la Sagra", Anales Toledanos, XXVI, 1989, pp. 233-275.

Pérez Sánchez, A. E., D. Antonio de Pereda 1611-1678 y la pintura madrileña de su tiempo, Madrid, 1979.

Pérez Sánchez, A. E., "La pintura toledana contemporánea de El Greco", en El Toledo de El Greco, cat. exp., Toledo, Ministerio de Cultura, 1982, pp. 131-210.

Revuelta Tubino, Matilde, Museo de Santa Cruz de Toledo. Sección de Bellas Artes I: siglos XIV, XV y XVI, Toledo, 1987.

Fecha de recepción: 17-I-2013

Fecha de aceptación: 10-III-2014 